\title{
Glomerular filtration rate affects interpretation of pulmonary function test in a Korean general population: results from the Korea National Health and Nutrition Examination Survey 2010 to 2012
}

Young Soo Kim ${ }^{1}$, Hee Yeon Kim ${ }^{1}$, Hyo-Suk Ahn ${ }^{1}$, Tae Seo Sohn' ${ }^{1}$ Jae Yen Song ${ }^{1}$, Young Bok Lee ${ }^{1}$, Dong-Hee Lee ${ }^{1}$, Jae-Im Lee ${ }^{1}$, Tae-Kyu Lee ${ }^{1}$, Seong Cheol Jeong ${ }^{1}$, Mihee Hong ${ }^{1}$, Hiun Suk Chae ${ }^{1}$, Kyungdo $\mathrm{Han}^{2}$, and Chang Dong Yeo ${ }^{1}$

${ }^{1}$ Epidemiology Study Cluster, College of Medicine, Uijeongbu St. Mary's Hospital, The Catholic University of Korea, Uijeongbu; ${ }^{2}$ Department of Biostatistics, College of Medicine, The Catholic University of Korea, Seoul, Korea
Received: May 27, 2015

Revised : June 22, 2015

Accepted: July 6, 2015

\section{Correspondence to}

Chang Dong Yeo, M.D.

Division of Pulmonology,

Department of Internal Medicine,

College of Medicine, Uijeongbu

St. Mary's Hospital, The Catholic

University of Korea, 271

Cheonbo-ro, Uijeongbu 11765 ,

Korea

Tel: $+82-31-820-3893$

Fax: $+82-31-820-3747$

E-mail: brainyeo@catholic.ac.kr
Background/Aims: The pulmonary abnormalities (principally restrictive abnormalities) are characteristic of renal transplant recipients or those with end-stage renal disease. Our aim was to explore whether the prevalence of spirometric abnormalities was influenced by the estimated glomerular filtration rates (GFRs) in a Korean general population.

Methods: We used data obtained during the 2010 to 2012 Korean National Health and Nutrition Examination Survey, a national cross-sectional survey. We analyzed data from subjects for whom spirometric assays and estimated GFRs were of acceptable quality.

Results: A total of 8,809 subjects (3,868 male and 4,941 female) was included. In both males and females with GFR values $<60 \mathrm{~mL} / \mathrm{min} / 1.73 \mathrm{~m}^{2}$, the linear trends toward the presence of obstructive and restrictive patterns were significant. However, the percent predicted forced vital capacity (FVC) decreased with a decline in the estimated GFR, but only in males ( $p$ for trend $<0.0031$ ). Multivariate linear regression analysis showed a decline in the estimated GFR was independently associated with falls in the percent predicted FVC and the forced expiratory volume in 1 second/FVC ratio in both males and females. However, the percent predicted FVC was independently predictive only in males $(p=0.002)$.

Conclusions: Impaired pulmonary function was associated with a decline in the estimated GFR. The percent predicted FVC decrease paralleled the decline in estimated GFR in male only. Careful interpretation of pulmonary function test data is required in patients with decreased GFRs or impaired renal function, especially males.

Keywords: Respiratory function tests; Glomerular filtration rate

\section{INTRODUCTION}

Chronic kidney disease (CKD) is a general term describ- ing heterogeneous disorders affecting kidney structure and function [1]. CKD is defined by the presence of kidney damage or a glomerular filtration rate (GFR) 
less than $60 \mathrm{~mL} / \mathrm{min} / 1.73 \mathrm{~m}^{2}$ for 3 or more months, irrespective of cause [2]. The median rate age-related GFR decline is 0.75 to $1.00 \mathrm{~mL} / \mathrm{min} / 1.73 \mathrm{~m}^{2}$ per 1 year [3]. In the USA, the prevalence of CKD is about $11.5 \%$, but attains $47 \%$ in subjects older than 70 years [4]. The increased prevalence of CKD, high treatment costs, and poor outcomes, burden public health systems worldwide.

Chronic obstructive pulmonary disease (COPD) is a leading cause of morbidity and mortality worldwide, imposing substantial and rising economic and social burdens [5]. COPD is diagnosed via spirometry; a postbronchodilator forced expiratory volume in 1 second $\left(\mathrm{FEV}_{1}\right) /$ forced vital capacity (FVC) ratio of less than 0.7 indicates persistent airflow limitation and (thus) COPD [6]. Restrictive ventilatory defects are characterized by reductions in total lung capacity (TLC) but normal $\mathrm{FEV}_{1} /$ FVC ratios [6]. TLC and residual lung volume are sometimes not measured, but a restrictive abnormality may be suspected when the FVC is reduced [6]. Spirometric data must be carefully interpreted in patients with dyspnea, chronic cough, and/or sputum production. The FVC, $\mathrm{FEV}_{1}$, and $\mathrm{FEV}_{1} / \mathrm{FVC}$ ratio are the fundamental parameters used to evaluate lung function [6].

Pulmonary complications, including edema, fibrosis, calcification, pleural effusion, and respiratory muscle myopathy, are common in CKD patients [7]. These conditions alter pulmonary function, reducing the FVCs of those with restrictive disorders, indicative of pulmonary congestion, decreased respiratory muscle strength, and hypoxemia $[8,9]$. Obstructive abnormalities have also been reported in CKD patients; however, in patients with $\mathrm{CKD}$, reductions in $\mathrm{FEV}_{1}$ are attributable primarily to falls in the FVC $[10,11]$. Pulmonary function improves significantly after successful renal transplantation [8]. The pulmonary abnormalities mentioned above are characteristic of renal transplant recipients or those with end-stage renal disease. Data on the relationships between spirometric parameters and the GFRs of general populations are lacking.

Our aim was to explore whether the prevalence of spirometric abnormalities was influenced by the estimated GFRs and gender in a Korean general population. Such data would assist clinicians who must interpret pulmonary function test results.

\section{METHODS}

\section{Study population}

We used data obtained during the 2010 to 2012 Korean National Health and Nutrition Examination Survey (KNHANES); this was a national cross-sectional survey conducted by the Ministry of Health and Welfare of Korea. The target population was non-institutionalized civilians aged $\geq 18$ years. Sampling units were households selected via a stratified, multistage probability-sampling design that considered geographic area, sex, and age group, by reference to household registries. A total of 25,661 subjects was included. The probability of being sampled was weighted for each participant; the results are thus representative of the entire Korean population. All participants completed a four-part questionnaire exploring health, health behavior, health examinations, and nutrition. Pulmonary function test data from subjects aged $<40$ years were excluded. Subjects with white blood cell counts $>10,000$ cells $/ \mu \mathrm{L}$ were also excluded; acute disease was possible. Finally, 8,809 subjects (3,868 males and 4,941 females) were included. Written informed consent was obtained from all subjects. The study was approved by the Institutional Review Board (IRB) of Korea Centers for Disease Control and Prevention (IRB: 2010-02CON-21-C, 2011-02CON-o6-C, 2012-01EXP-01-2C).

\section{Data collection}

During the 2010 to 2012 KNHANES, all candidate participants were informed that they had been randomly selected to voluntarily participate in a national representative survey conducted by the Ministry of Health and Welfare of Korea in 2012, and that they could refuse to participate under the National Health Enhancement Act supported by the National Statistics Law of Korea. Health examinations (conducted in 2010 to 2012) included medical history-taking, physical examination, administration of a questionnaire exploring healthrelated behaviors, anthropometric measurements, and collection of biochemical data. All physical examinations were performed by trained medical staff who followed a standard procedure. Cigarette smoking, alcohol consumption, and current treatment for any disease were investigated. If any disease was being treated, the subject was asked to give the diagnosis and a list of medications 
currently taken. Completed questionnaires were reviewed by trained staff and entered into a database. Body weight and height were measured with subjects wearing light indoor clothing, without shoes, to the nearest 0.1 $\mathrm{kg}$ and $0.1 \mathrm{~cm}$, respectively. The body mass index (BMI) was the weight $/$ height $^{2}$ (thus, $\mathrm{kg} / \mathrm{m}^{2}$ ). Blood pressure in the right arm was measured using a standard mercury sphygmomanometer (Baumanometer, Baum, Copiague, NY, USA). Waist circumference (WC) was measured by trained staff using standard protocol. Systolic and diastolic blood pressure readings were recorded twice over a 5-minute interval and averaged prior to analysis. After a 12-hour overnight fast, blood samples were obtained from antecubital veins, centrifuged, refrigerated the examination sites, and transferred on ice on the same day to a central laboratory in Seoul. Fasting levels of plasma glucose, total cholesterol, triglyceride, high density lipoprotein (HDL) cholesterol, and creatinine were measured using an ADVIA1650 autoanalyzer (Siemens Medical Solutions Diagnostics, Erlangen, Germany). The estimated GFR was calculated using the CrockcroftGault formula [4], as follows: GFR $=[(140-$ age in year $\times$ weight in $\mathrm{kg}) /\left(0.81 \times\right.$ creatinine level $\left.\left.\mu \mathrm{mol} / \mathrm{L} \times 1.73 \mathrm{~m}^{2}\right)\right]$ / $\operatorname{BSA}\left(\mathrm{m}^{2}\right)(\times 0.85$ only if female).

\section{Spirometry}

Trained interviewers visited the homes of all subjects and administered a standardized questionnaire on physician-diagnosed diseases. A few days later, spirometry was performed by trained technicians who followed the 1994 recommendations of the American Thoracic Society for which a dry rolling seal spirometer (Model 2130, SensorMedics, Yorba Linda, CA, USA) [12]. We analyzed only data obtained from subjects for whom two or more spirometric assays were of acceptable quality. The FVC, $\mathrm{FEV}_{1}$, and $\mathrm{FEV}_{1} / \mathrm{FVC}$ ratio were measured. Restrictive lung disease was considered present when the percent predicted FVC was less than $80 \%$ and the $\mathrm{FEV}_{1} / \mathrm{FVC}$ ratio was greater than o.7. Chest X-rays were also obtained, using specially dedicated mobile platforms; two radiologists evaluated all X-ray films. The spirometric and Xray procedures have been described in detail elsewhere [13].

\section{Statistical analysis}

Data are expressed as frequencies with percentages, or as means with standard errors. The basic characteristics of the study population (in terms of estimated GFRs) were compared using the unpaired Student $t$ test for continuous variables and the chi-square test for categorical variables. Pearson correlation coefficients were determined between the GFR and the clinical variables of age, BMI, WC, and blood pressure; and the levels of glucose, total cholesterol, triglycerides, HDL, and creatinine. Multiple linear regression analysis was used to search for independent relationships between FVC (\%) and the $\mathrm{FEV}_{1} /$ FVC ratio, and other clinical variables. A linear-by-linear association test was employed to explore associations between a decline in the estimated GFR, and pulmonary function patterns or changes in FVC (\%) and the $\mathrm{FEV}_{1} /$ FVC ratio. SAS version 9.1 (SAS Institute Inc., Cary, NC, USA) for Windows was used in analysis, and a $p<0.05$ was taken to reflect significance.

\section{RESULTS}

\section{Clinical characteristics by estimated GFR}

Table 1 shows the characteristics of 3,868 male and 4,941 female subjects by their estimated GFRs. CKD is defined as a GFR $<60 \mathrm{~mL} / \mathrm{min} / 1.73 \mathrm{~m}^{2}$ for 3 months or more [1]; we used this definition in analysis.

Males with GFRs $<60 \mathrm{~mL} / \mathrm{min} / 1.73 \mathrm{~m}^{2}$ were likely to be of older age; to have a lesser smoking history; to have elevated levels of serum creatinine; and to exhibit features of metabolic syndrome including a high BMI, hypertension, DM, and WC, compared with those with GFRs $\geq 60 \mathrm{~mL} / \mathrm{min} / 1.73 \mathrm{~m}^{2}$. Males with GFRs $<60 \mathrm{~mL} /$ $\min / 1.73 \mathrm{~m}^{2}$ had lower-than-predicted FVC values and $\mathrm{FEV}_{1} / \mathrm{FVC}$ ratios upon spirometry. Females with lower GFRs tended to be of older age, and to have hypertension, DM, metabolic syndrome, and an enhanced WC. Upon spirometry, females with GFRs $<60 \mathrm{~mL} / \mathrm{min} / 1.73$ $\mathrm{m}^{2}$ exhibited reduced the percent predicted FVC, percent predicted $\mathrm{FEV}_{1}$ values, and $\mathrm{FEV} / \mathrm{FVC}$ ratio compared with those with GFRs $\geq 60 \mathrm{~mL} / \mathrm{min} / 1.73 \mathrm{~m}^{2}$.

\section{Association of spirometric abnormalities with a fall in the GFR}

We defined a restrictive pattern as a percent predicted FVC less than $80 \%$ and an $\mathrm{FEV}_{1} / \mathrm{FVC}$ ratio greater than 0.7; and an obstructive pattern as an $\mathrm{FEV}_{1} / \mathrm{FVC}$ ratio be- 
low o.7. In both males and females with GFR values $<60$ $\mathrm{mL} / \mathrm{min} / 1.73 \mathrm{~m}^{2}$, the linear trends toward the presence of obstructive and restrictive patterns were significant (Fig. 1). Fig. 2 shows that the percent predicted FVC decreased with a decline in the estimated GFR, but only in males (a linear-by-linear association was evident, with a $p$ for trend $<0.0031)$. In both males and females, a decreased $\mathrm{FEV}_{1} / \mathrm{FVC}$ ratio was significantly associated with a decline in the estimated GFR.

\section{Correlations between the GFR and spirometric parameters}

The Pearson's correlation data are shown in Table 2. In both males and females, the $\mathrm{FEV}_{1} / \mathrm{FVC}$ ratio correlated significantly with the estimated GFR, which was positively associated with the percent predicted FVC only in males, and negatively associated with the percent predicted FEV ${ }_{1}$ only in females.

Table 3 shows the results of multivariate linear regres-

Table 1. Clinical characteristics of the study population

\begin{tabular}{|c|c|c|c|c|c|c|}
\hline \multirow[b]{2}{*}{ Characteristic } & \multicolumn{3}{|c|}{ Male $(\mathrm{n}=3,868)$} & \multicolumn{3}{|c|}{ Female $(n=4,941)$} \\
\hline & $\begin{array}{l}\text { GFR } \geq 60 \\
(n=3,741)\end{array}$ & $\begin{array}{c}\text { GFR }<60 \\
(n=127)\end{array}$ & $p$ value & $\begin{array}{l}\mathrm{GFR} \geq 60 \\
(\mathrm{n}=4,818)\end{array}$ & $\begin{array}{c}\mathrm{GFR}<60 \\
(\mathrm{n}=123)\end{array}$ & $p$ value \\
\hline Age, yr & $52.9 \pm 0.2$ & $64.5 \pm 1.2$ & 0.001 & $54.5 \pm 0.2$ & $68.4 \pm 1.1$ & 0.001 \\
\hline Smoking, \% & $40.2(1.1)$ & $25.4(5.2)$ & 0.014 & $4.2(0.4)$ & $5.4(2.1)$ & 0.536 \\
\hline Body mass index, $\mathrm{kg} / \mathrm{m}^{2}$ & $24.4 \pm 0.1$ & $25.1 \pm 0.3$ & 0.036 & $24.2 \pm 0.1$ & $25 \pm 0.4$ & 0.054 \\
\hline Waist circumference, $\mathrm{cm}$ & $85.9 \pm 0.2$ & $88.5 \pm 0.9$ & 0.006 & $80.9 \pm 0.2$ & $84.9 \pm 1.1$ & 0.001 \\
\hline High blood pressure, \% & $40.3(1)$ & $85.4(3.4)$ & 0.001 & $33.6(1)$ & $74.3(4.8)$ & 0.001 \\
\hline Diabetes mellitus, \% & $12.9(0.7)$ & $36.5(5 \cdot 5)$ & 0.001 & $9.3(0.5)$ & $37.9(5.6)$ & 0.001 \\
\hline Metabolic syndrome, \% & $35 \cdot 5(1)$ & $61.5(5 \cdot 5)$ & 0.001 & $35.9(0.9)$ & $73.9(4.9)$ & 0.001 \\
\hline Creatinine, mg/dL & $1.0 \pm 0.0$ & $1.5 \pm 0.0$ & 0.001 & $0.7 \pm 0.0$ & $1.3 \pm 0.1$ & 0.001 \\
\hline $\mathrm{GFR}, \mathrm{mL} / \mathrm{min} / 1.73 \mathrm{~m}^{2}$ & $90.2 \pm 0.4$ & $50.9 \pm 0.9$ & 0.001 & $93.4 \pm 0.3$ & $50.9 \pm 1.3$ & 0.001 \\
\hline $\mathrm{FEV}_{1} \%$ predicted & $90.4 \pm 0.3$ & $87.9 \pm 1.6$ & 0.119 & $94.3 \pm 0.3$ & $93.8 \pm 1.5$ & 0.001 \\
\hline FVC \% predicted & $92.7 \pm 0.2$ & $86.7 \pm 1.3$ & 0.001 & $94.3 \pm 0.2$ & $90.7 \pm 1.3$ & 0.006 \\
\hline $\mathrm{FEV}_{1} / \mathrm{FVC}$ & $0.8 \pm 0.0$ & $0.7 \pm 0.0$ & 0.001 & $0.8 \pm 0.0$ & $0.8 \pm 0.0$ & 0.001 \\
\hline
\end{tabular}

Values are presented as mean \pm SE or number (\%).

GFR, glomerular filtration rate; $\mathrm{FEV}_{1}$, forced expiratory volume in 1 second; FVC, forced vital capacity.
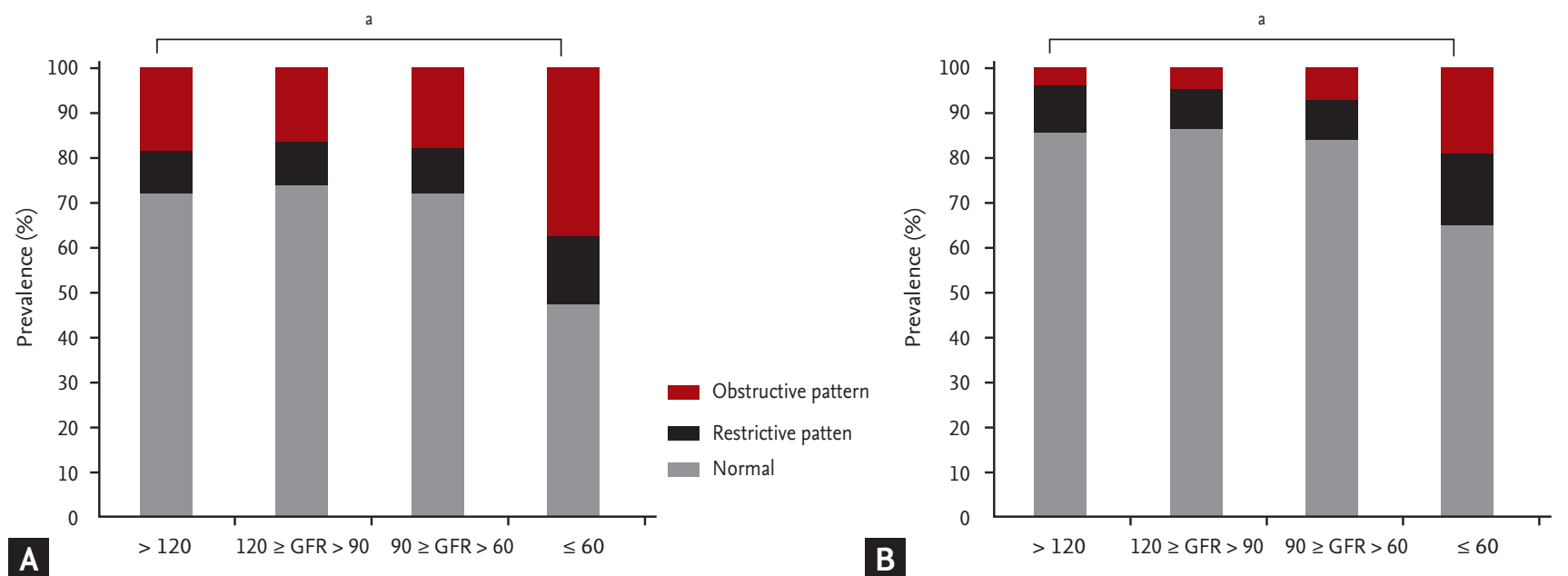

Figure 1. Trends in pulmonary function abnormalities with declines in the estimated glomerular filtration rates (GFRs) of (A) males and (B) females. ${ }^{a} p<0.0001$. 

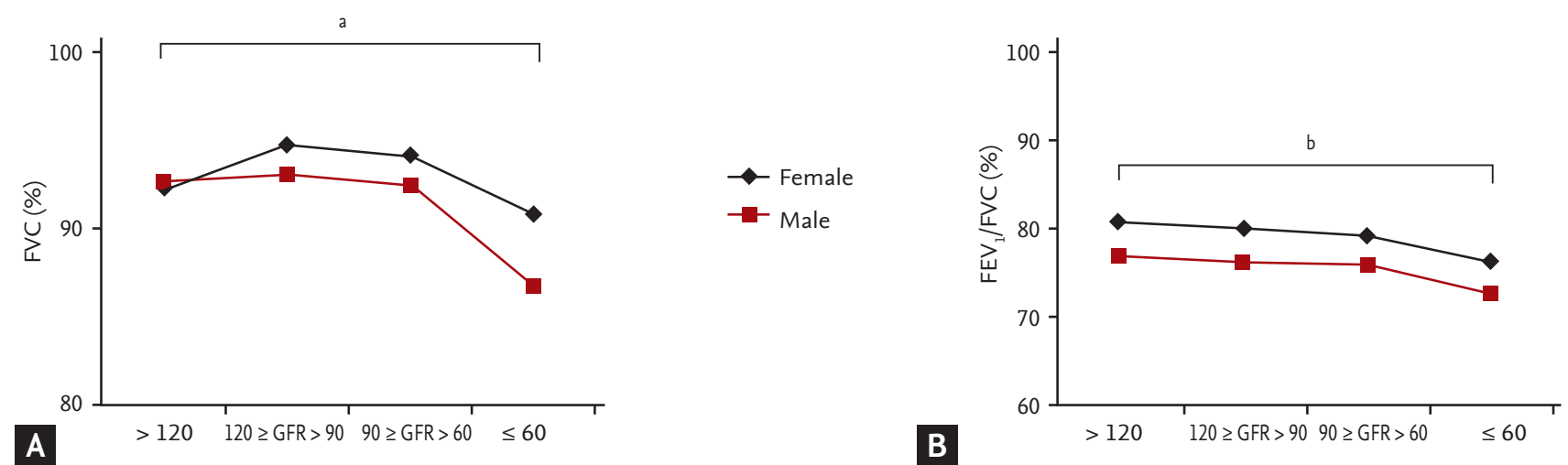

Figure 2. Changes in percent predicted (A) forced vital capacity (FVC) and the (B) forced expiratory volume in 1 second $\left(\mathrm{FEV}_{\mathrm{1}}\right) /$ FVC ratio with a decline in the estimated glomerular filtration rate (GFR). ${ }^{a} p<0.0001$ for males only, ${ }^{b} p<0.0001$ for both males and females.

Table 2. Correlations between glomerular filtration rate and other clinical variables

\begin{tabular}{|c|c|c|c|c|}
\hline \multirow{2}{*}{ Characteristic } & \multicolumn{2}{|c|}{ Male } & \multicolumn{2}{|c|}{ Female } \\
\hline & $r$ & $p$ value & $r$ & $p$ value \\
\hline Age, yr & -0.205 & 0.001 & -0.316 & 0.001 \\
\hline Body mass index, $\mathrm{kg} / \mathrm{m}^{2}$ & -0.159 & 0.001 & -0.022 & 0.280 \\
\hline Waist circumference, $\mathrm{cm}$ & -0.123 & 0.001 & -0.045 & 0.025 \\
\hline Systolic blood pressure, $\mathrm{mmHg}$ & -0.031 & 0.142 & -0.088 & 0.001 \\
\hline Diastolic blood pressure, $\mathrm{mmHg}$ & 0.005 & 0.819 & 0.019 & 0.302 \\
\hline Glucose, mg/dL & 0.018 & 0.360 & -0.048 & 0.023 \\
\hline Total cholesterol, mg/dL & -0.024 & 0.243 & -0.031 & 0.088 \\
\hline Triglyceride, mg/dL & -0.040 & 0.070 & -0.061 & 0.001 \\
\hline High density lipoprotein, mg/dL & 0.136 & 0.001 & 0.065 & 0.001 \\
\hline Creatinine, $\mathrm{mg} / \mathrm{dL}$ & -0.899 & 0.001 & -0.706 & 0.001 \\
\hline FVC $\%$ predicted & 0.073 & 0.001 & 0.007 & 0.687 \\
\hline $\mathrm{FEV}_{1} \%$ predicted & -0.003 & 0.892 & -0.042 & 0.019 \\
\hline $\mathrm{FEV}_{1} / \mathrm{FVC}$ ratio & 0.065 & 0.001 & 0.123 & 0.001 \\
\hline
\end{tabular}

Pearson's correlation coefficients were determined for glomerular filtration rate versus other variables.

$\mathrm{FVC}$, forced vital capacity; $\mathrm{FEV}_{1}$, forced expiratory volume in 1 second.

sion analysis of the relationship between the estimated GFR and spirometric parameters. Older age, a higher BMI, a greater WC, and elevated blood pressure, independently predicted the percent predicted FVC and the $\mathrm{FEV}_{1} / \mathrm{FVC}$ ratio. In both males and females, a decline in the estimated GFR was independently associated with falls in the percent predicted FVC and the $\mathrm{FEV}_{1} / \mathrm{FVC}$ ratio. However, the percent predicted FVC was independently predictive only in males $(p=0.002)$.

\section{DISCUSSION}

We investigated the association between pulmonary functional abnormalities and the estimated GFR, by gender, in a general Korean population. The percent predicted $\mathrm{FVC}$ and the $\mathrm{FEV}_{1} / \mathrm{FVC}$ ratio declined as the estimated GFR decreased. However, the percent predicted FVC was independently associated with the GFR fall only in males. Thus, changes in pulmonary functioning, including declines in the FVC and $\mathrm{FEV}_{1} / \mathrm{FVC}$ ratio 
Table 3. Results of multiple linear regression analysis seeking independent relationships between $\mathrm{FVC}_{\text {, the }} \mathrm{FEV}_{\mathbf{1}} / \mathrm{FVC}$ ratio, and other clinical variables

\begin{tabular}{|c|c|c|c|c|c|c|c|c|}
\hline \multirow{3}{*}{ Characteristic } & \multicolumn{4}{|c|}{ Male } & \multicolumn{4}{|c|}{ Female } \\
\hline & \multicolumn{2}{|c|}{ FVC } & \multicolumn{2}{|c|}{$\mathrm{FEV}_{1} / \mathrm{FVC}$} & \multicolumn{2}{|c|}{ FVC } & \multicolumn{2}{|c|}{$\mathrm{FEV}_{1} / \mathrm{FVC}$} \\
\hline & $r$ & $p$ value & $r$ & $p$ value & $r$ & $p$ value & $r$ & $p$ value \\
\hline Age, yr & -0.208 & 0.001 & -0.479 & 0.001 & -0.080 & 0.001 & -0.359 & 0.001 \\
\hline BMI, $\mathrm{kg} / \mathrm{m}^{2}$ & -0.234 & 0.001 & 0.172 & 0.001 & -0.164 & 0.001 & 0.075 & 0.001 \\
\hline $\mathrm{WC}, \mathrm{cm}$ & -0.257 & 0.001 & 0.016 & 0.432 & -0.176 & 0.001 & -0.013 & 0.048 \\
\hline $\mathrm{SBP}, \mathrm{mmHg}$ & -0.137 & 0.001 & -0.107 & 0.001 & -0.116 & 0.001 & -0.085 & 0.001 \\
\hline $\mathrm{DBP}, \mathrm{mmHg}$ & -0.014 & 0.471 & 0.117 & 0.001 & -0.047 & 0.016 & 0.042 & 0.040 \\
\hline Glucose, mg/dL & -0.095 & 0.001 & -0.012 & 0.550 & -0.145 & 0.001 & -0.012 & 0.439 \\
\hline Total cholesterol, mg/dL & 0.019 & 0.350 & 0.071 & 0.001 & -0.048 & 0.009 & -0.046 & 0.007 \\
\hline Triglyceride, mg/dL & -0.102 & 0.001 & 0.069 & 0.001 & -0.120 & 0.001 & -0.030 & 0.091 \\
\hline $\mathrm{HDL}, \mathrm{mg} / \mathrm{dL}$ & 0.131 & 0.001 & -0.025 & 0.280 & 0.066 & 0.001 & -0.009 & 0.610 \\
\hline Creatinine, mg/dL & -0.058 & 0.007 & 0.016 & 0.346 & -0.001 & 0.988 & -0.042 & 0.004 \\
\hline GFR, $\mathrm{mL} / \mathrm{min} / 1.73 \mathrm{~m}^{2}$ & 0.073 & 0.001 & 0.065 & 0.001 & 0.007 & 0.687 & 0.123 & 0.001 \\
\hline
\end{tabular}

FVC, forced vital capacity; $\mathrm{FEV}_{1}$, forced expiratory volume in 1 second; BMI, body mass index; WC, waist circumference; SBP, systolic blood pressure; DBP, diastolic blood pressure; HDL, high density lipoprotein; GFR, glomerular filtration rate.

should be considered when pulmonary function test results of patients with CKD are interpreted.

Impaired pulmonary function has been reported in patients with metabolic syndrome, proteinuria, and diabetes mellitus [14-16]. We found that metabolic syndrome components including hypertension, hyperglycemia, dyslipidemia, and abdominal obesity were associated with impaired pulmonary function in both males and females, in agreement with previous findings [14]. Possible explanations are that abdominal obesity affects thoracic and diaphragm compliance, and that inflammation associated with insulin-resistance might be an early trigger of lung function decline $[16,17]$. Microalbuminuria has been reported to be associated with a restrictive pattern and lower than predicted FVCs in a Korean general population [15]. Microalbuminuria is an early predictor of both kidney damage and atherosclerosis [18]. A reduced FVC has been linked to atherogenic diseases including diabetes and hypertension, and mortality rises when the restrictive pattern coexists with such chronic diseases [19,20].

CKD is a major risk factor for cardiovascular disease; mortality from such disease is 10- to 30-fold higher in dialysis patients $[1,21]$. A lower GFR, albuminuria, and other traditional risk factors including hypertension, fluid overload, electrolyte and acid-base disorders, inflammation, oxidative stress, and prothrombotic stimuli, increase the risk of cardiovascular disease [22,23]. A restrictive pattern may reflect stiffening of the lung parenchyme, chronic fluid engorgement, loss of lung volume caused by ingress of alveolar and interstitial fluid, and increased heart size. In addition, cardiomegaly caused by cardiovascular disease is, at least in part, responsible for development of restrictive lung disease $[24,25]$. We hypothesize that abdominal obesity, systemic inflammation associated with atherosclerosis, and cardiovascular disease and complications thereof, may explain the impaired pulmonary function of patients with decreased GFRs.

Another noteworthy finding was that gender differences were evident. Declines in the percent predicted FVC were significantly associated with GFRs in males but not females. Earlier reports found that metabolic syndrome and microalbuminuria were independently associated with declines in the FVC and development of restrictive abnormalities in males [15,26]. Although the literature does not explain the observed gender differences, possible reasons include differential sex hormone actions and structural/morphological between-gender effects [27]. Svartberg et al. [28] found that reduced pul- 
monary function was associated with low levels of endogenous total and free testosterone. In addition, the female airway is smaller (relative to lung size) than that of the male [29].

When interpreting pulmonary function test data, the $\mathrm{FEV}_{1} / \mathrm{FVC}, \mathrm{FEV}_{1}$ and FVC should be considered first. The post-bronchodilator $\mathrm{FEV}_{1} / \mathrm{FVC}$ ratio is the best indicator of an obstructive abnormality. TLC should be used to confirm or exclude the presence of a restrictive abnormality when the vital capacity is below the lower limit of normal [6]. Interpretations require comparison of patient findings with reference (predicted) values derived from healthy subjects with identical anthropometric characteristics (e.g., sex, age, and height) and, where relevant, of the same ethnicity [30]. Spirometric reference data were earlier derived, in Korea, for use in the KNHANES [31].

When $\mathrm{FEV}_{1}$ and FVC are concomitantly decreased and the $\mathrm{FEV}_{\mathrm{l}} / \mathrm{FVC}$ ratio is normal or near-normal, the presence of an obstruction cannot be ruled out by simple measurement of $\mathrm{FEV}_{1}$ and FVC. An obstruction may render the airflow so slow that the subject cannot empty the lungs [6]. Another possible cause of an obstruction is patch collapse of small airways early in exhalation [32]. Under such circumstances, TLC must be measured to confirm or exclude the presence of a restrictive defect when the vital capacity is below the lower limit of normal [6]. We hypothesized that a decreased FVC, a normal or near-normal $\mathrm{FEV}_{1} / \mathrm{FVC}$ ratio, and a TLC equal to or greater than the lower limit of normal, suggested the presence of an obstructive abnormality. Therefore, when patients with CKD are suspected to have COPD, a decreased FVC with a normal or near-normal $\mathrm{FEV}_{1} / \mathrm{FVC}$ ratio dose not clearly exclude an obstructive abnormality, especially in males. Lung volume must be measured.

Our study had some limitations. As few data on postbronchodilator spirometric parameters or lung volumes were available, we used only $\mathrm{FEV}_{1}$, FVC, and the $\mathrm{FEV}_{1} /$ FVC ratio in analysis. Further prospective studies of post-bronchodilator responses, with measurement of lung volumes, are required. Another limitation is that a single measure of an estimated GFR of less than $60 \mathrm{~mL} /$ $\min / 1.73 \mathrm{~m}^{2}$ was considered to reflect CKD; GFRs were not measured over 3 or more months. As the study was cross-sectional in design, a few subjects with acute kidney injuries may have been enrolled.
In conclusion, we found that impaired pulmonary function was associated with a decline in the estimated GFR. The $\mathrm{FEV}_{1} / \mathrm{FVC}$ ratio, a spirometric index of airflow limitation, decreased when the estimated GFR declined in both males and females. In males only, the percent predicted FVC decrease paralleled the decline in estimated GFR. Careful interpretation of pulmonary function test data is required in patients with decreased GFRs or impaired renal function, especially males.

\section{KEY MESSAGE}

1. In both males and females with glomerular filtration rate (GFR) values $<60 \mathrm{~mL} / \mathrm{min} / 1.73$ $\mathrm{m}^{2}$, the linear trends toward the presence of obstructive and restrictive patterns were significant.

2. The percent predicted forced vital capacity (FVC) decreased with a decline in the estimated GFR, but only in males.

3. A decline in the estimated GFR was independently associated with falls in the percent predicted FVC and the forced expiratory volume in 1 second/FVC ratio in both males and females.

\section{Conflict of interest}

No potential conflict of interest relevant to this article was reported.

\section{REFERENCES}

1. Levey AS, Coresh J. Chronic kidney disease. Lancet 2012;379:165-180.

2. Stevens LA, Levey AS. Current status and future perspectives for CKD testing. Am J Kidney Dis 2009;53(3 Suppl 3):S17-S26.

3. Stevens LA, Coresh J, Greene T, Levey AS. Assessing kidney function: measured and estimated glomerular filtration rate. N Engl J Med 2006;354:2473-2483.

4. Levey AS, Bosch JP, Lewis JB, Greene T, Rogers N, Roth D. A more accurate method to estimate glomerular filtration rate from serum creatinine: a new prediction equation. Modification of Diet in Renal Disease Study Group. Ann 
Intern Med 1999;130:461-470.

5. Vestbo J, Hurd SS, Agusti AG, et al. Global strategy for the diagnosis, management, and prevention of chronic obstructive pulmonary disease: GOLD executive summary. Am J Respir Crit Care Med 2013;187:347-365.

6. Pellegrino R, Viegi G, Brusasco V, et al. Interpretative strategies for lung function tests. Eur Respir J 2005;26:948968.

7. Prezant DJ. Effect of uremia and its treatment on pulmonary function. Lung 1990;168:1-14.

8. Sidhu J, Ahuja G, Aulakh B, Narang A, Whig J, Sidhu U. Changes in pulmonary function in patients with chronic renal failure after successful renal transplantation. Scand J Urol Nephrol 2007;41:155-160.

9. Karacan O, Tutal E, Colak T, Sezer S, Eyuboglu FO, Haberal M. Pulmonary function in renal transplant recipients and end-stage renal disease patients undergoing maintenance dialysis. Transplant Proc 2006;38:396-400.

10. Pride NB. Tests of forced expiration and inspiration. Clin Chest Med 2001;22:599-622, vii.

11. Paul K, Mavridis G, Bonzel KE, Scharer K. Pulmonary function in children with chronic renal failure. Eur J Pediatr 1991;150:808-812.

12. American Thoracic Society. Standardization of spirometry, 1994 update. Am J Respir Crit Care Med 1995;152:11071136.

13. Kim DS, Kim YS, Jung KS, et al. Prevalence of chronic obstructive pulmonary disease in Korea: a populationbased spirometry survey. Am J Respir Crit Care Med 2005;172:842-847.

14. Chen WL, Wang CC, Wu LW, et al. Relationship between lung function and metabolic syndrome. PLoS One 2014;9:e108989.

15. 1 Yoon JH, Won JU, Ahn YS, Roh J. Poor lung function has inverse relationship with microalbuminuria, an early surrogate marker of kidney damage and atherosclerosis: the 5th Korea National Health and Nutrition Examination Survey. PLoS One 2014;9:e94125.

16. Tiengo A, Fadini GP, Avogaro A. The metabolic syndrome, diabetes and lung dysfunction. Diabetes Metab 2008;34:447-454.

17. Salome CM, King GG, Berend N. Physiology of obesity and effects on lung function. J Appl Physiol (1985) 2010;108:206-211.

18. Garg JP, Bakris GL. Microalbuminuria: marker of vascular dysfunction, risk factor for cardiovascular disease.
Vasc Med 2002;7:35-43.

19. Johnston AK, Mannino DM, Hagan GW, Davis KJ, Kiri VA. Relationship between lung function impairment and incidence or recurrence of cardiovascular events in a middle-aged cohort. Thorax 2008;63:599-605.

20. Mannino DM, Holguin F, Pavlin BI, Ferdinands JM. Risk factors for prevalence of and mortality related to restriction on spirometry: findings from the First National Health and Nutrition Examination Survey and follow-up. Int J Tuberc Lung Dis 2005;9:613-621.

21. Sarnak MJ, Levey AS, Schoolwerth AC, et al. Kidney disease as a risk factor for development of cardiovascular disease: a statement from the American Heart Association Councils on Kidney in Cardiovascular Disease, High Blood Pressure Research, Clinical Cardiology, and Epidemiology and Prevention. Hypertension 2003;42:1050-1065.

22. Shlipak MG, Fried LF, Cushman M, et al. Cardiovascular mortality risk in chronic kidney disease: comparison of traditional and novel risk factors. JAMA 2005;293:17371745 .

23. Schiffrin EL, Lipman ML, Mann JF. Chronic kidney disease: effects on the cardiovascular system. Circulation 2007;116:85-97.

24. Agostoni P, Cattadori G, Guazzi M, Palermo P, Bussotti M, Marenzi G. Cardiomegaly as a possible cause of lung dysfunction in patients with heart failure. Am Heart J 2000;140:e24.

25. Guazzi M, Agostoni P, Matturri M, Pontone G, Guazzi MD. Pulmonary function, cardiac function, and exercise capacity in a follow-up of patients with congestive heart failure treated with carvedilol. Am Heart J 1999;138(3 Pt 1):460-467.

26. Choi JH, Park S, Shin YH, Kim MY, Lee YJ. Sex differences in the relationship between metabolic syndrome and pulmonary function: the 2007 Korean National Health and Nutrition Examination Survey. Endocr J 2011;58:459465.

27. Harms CA. Does gender affect pulmonary function and exercise capacity? Respir Physiol Neurobiol 2006;151:124131.

28. Svartberg J, Schirmer H, Medbo A, Melbye H, Aasebo U. Reduced pulmonary function is associated with lower levels of endogenous total and free testosterone. The Tromso study. Eur J Epidemiol 2007;22:107-112.

29. Mead J. Dysanapsis in normal lungs assessed by the relationship between maximal flow, static recoil, and vital 
capacity. Am Rev Respir Dis 1980;121:339-342.

30. Lung function testing: selection of reference values and interpretative strategies. American Thoracic Society. Am Rev Respir Dis 1991;144:1202-1218.

31. Eom SY, Kim H. Reference values for the pulmonary function of Korean adults using the data of Korea National Health and Nutrition Examination Survey IV
(2007-2009). J Korean Med Sci 2013;28:424-430.

32. Quanjer PH, Tammeling GJ, Cotes JE, Pedersen OF, Peslin R, Yernault JC. Lung volumes and forced ventilatory flows: report working party standardization of Lung Function Tests, European Community for Steel and Coal. Official Statement of the European Respiratory Society. Eur Respir J Suppl 1993;16:5-40. 